\title{
Possible Antidiabetic Mechanism of Action of Ex-maradi Okra Fruit Variety (Abelmoscus esculentus) on Alloxan Induced Diabetic Rats
}

\author{
${ }^{*}$ A. Y. Abbas, ${ }^{2}$ I. Muhammad, ${ }^{3}$ M. B. AbdulRahman, ${ }^{1}$ L. S. Bilbis, ${ }^{1}$ Y. Saidu and ${ }^{1}$ A. Onu \\ 'Department of Biochemistry, Faculty of Science, Usmanu Danfodiyo University, Sokoto, Nigeria. \\ 2Department of Biochemistry, Faculty of Natural and applied Sciences, Umaru Musa Yaradua University, Katsina, Nigeria. \\ ${ }^{3}$ Department of Chemical Pathology and Imunology, Faculty of Basic Medicine, College of Health sciences, Usmanu Danfodiyo \\ University, Nigeria. \\ [“Corresponding Author: E-mail: ayabbas2002@yahoo.com]
}

\begin{abstract}
Increasing evidences suggest that postprandial hyperglycemia plays an important role in the development of diabetes complications. Therefore, therapeutic approaches that act via lowering of postprandial glucose leading to reduce insulin requirement are currently very attractive. The present study investigated some possible mechanisms of hypoglycemic action of different parts (Whole Okra 'WO'; Okra Peel 'OP' and Okra Seed 'OS') of Ex-maradi Okra fruit variety in the management of diabetes mellitus in alloxan induced diabetic rats. Standard analytical procedures were employed in the study. The results indicated that various parts of Okra fruit have ability to stimulate glycogen synthesis in the liver and delay intestinal absorption of glucose with very significant glucose dialysis retardation index (GDRI) and high glucose adsorption capacity (GAC). Histological examination of the pancreatic tissue after administration of Okra fruit revealed evidence of pancreatic islets cells regeneration. These results suggest that the possible mechanisms of antidiabetic effect of Okra fruit are multidimensional and might involve increased glycogenesis, delay glucose absorption and pancreatic islets regeneration leading to increased insulin secretion. These might help control postprandial hyperglycemia in diabetes mellitus.
\end{abstract}

Keywords: Diabetes, Glycogen, Glucose, Hyperglycemia, Okra

\section{INTRODUCTION}

Diabetes mellitus is a metabolic disorder characterized by chronic hyperglycemia with disturbances of carbohydrate, fat and protein metabolism resulting from defects in insulin secretion, insulin action or both (WHO, 1999). It is one of the most common chronic diseases in most countries and the number of people with diabetes has risen from 108 million in 1980 to 422 million in 2014 (WHO, 2016). In 2012, an estimated 1.5 million deaths were directly caused by diabetes and another 2.2 million deaths were attributable to high blood glucose. (WHO, 2016) Different medicinal plants have been explored for their antidiabetic properties, and several scientific findings have corroborated these claims (Etuk and Mohammed, 2009). There are several mechanisms that sought to explain the blood glucose lowering effects of antidiabetic plants. These include inhibition of carbohydrate metabolizing enzymes, inhibition of glucose absorption from intestine, enhancement of insulin sensitivity, regeneration of damaged pancreatic islet and $\beta$-cells, enhancement of insulin secretion and release, inhibition of glucose production from hepatocytes, enhancing glucose uptake by adipose and muscle tissues as well as plants that exhibit antioxidant effects (Shokeen et al., 2008; El-Abhar et al., 2014).

Okra (Abelmoschus esculentus (L) Moench) also known as ladies finger is an important vegetable crop of the Mallow family and native of tropical Africa (Habtamu et al., 2014). Okra is a tall annual dicotyledonous plant related to cotton and thought to be of African origin. (Nilesh et al., 2012). It forms edible capsules (fruits) which contains mucilaginous substances commonly use in making soups (Habtamu et al., 2014). The mucilage is also used as thickener in cooking as it can maintains its consistency both in its fresh or dry form after cooking (Habtamu et al., 2014). 
There is long tradition of using Okra in cooking as well as for traditional medicinal uses (Nilesh et al., 2012). Hence, the aim of this research is to investigate the ability of different parts (Whole Okra, Okra Peel and Okra Seed) of Ex- maradi Okra fruit variety on liver glycogen content, retardation of intestinal glucose absorption / diffusion and glucose adsorption capacity and pancreas $\beta$-cells regeneration in order to decipher the possible mechanism of its hypoglycemic effect.

\section{MATERIALS AND METHODS \\ Chemicals and Reagents}

Analytical grade laboratory chemicals and reagents were used for this study. Alloxan monohydrate and cellulose were purchased from Sigma-Aldrich, Mumbai, India. Glucose oxidase assay kit was purchased from Randox Laboratories Ltd. Antrim U.K. Sulphuric acid was bought from Fisher Scientific, UK and Hematoxylin \& Eosin (H\&E) stain kit was purchased from Vector Laboratories, UK.

\section{Okra Sample Collection}

Ex- maradi Okra fruit variety was selected for this study. The matured Okra fruits were purchased from Maggi market in Sokoto State, Nigeria. The sample was botanically identified and authenticated by a taxonomist in the Botany unit of the Department of Biological Sciences at Usmanu Danfidiyo University, Sokoto. A voucher specimen number (UDUH/ANS/0066) was assigned to the sample while the specimen sample was deposited in the Herbarium of the same Department.

\section{Okra Sample Preparation}

The Okra sample was thoroughly sorted to remove out any unwanted matter. Whole Okra fruit (WO) $(500 \mathrm{~g})$ was ground to powder using a mortar and pestle. The peels (OP) of another 500 $\mathrm{g}$ of the Okra fruit was obtained while the same procedure was repeated to obtain the seed (OS) both of which were ground to powder The powdered samples were sieved with a fine mesh, placed in a labeled sealed container and stored at normal laboratory conditions until needed.

\section{Experimental Animals}

Thirty two (32) apparently healthy Wistar strain albino rats of both sexes weighing between 120$150 \mathrm{~g}$ obtained from the Animal House of the Department of Biological Sciences, Usmanu Danfodiyo University, Sokoto, Nigeria were used for this study. The animals were kept for two (2) weeks at the animal house of the Department of Biochemistry, UDUS and maintained on pelletized growers feed with access to water ad libitum.

\section{Induction of Diabetes Mellitus}

Diabetes mellitus was induced following the method Saidu et al.,(2011) All experimental rats, except the normal control groups (normal rats fasted [NF] and normal rats fasted and refed[NFRU]) were intraperitoneally injected with $120 \mathrm{mg} / \mathrm{kg}$ body weight of the prepared alloxan. After 6 hours of alloxan administration, the experimental rats were then allowed accesses to $10 \%$ glucose solution for the next 24 hours in other to prevent alloxan induced hypoglycemia. The animals were observed for polydipsia, polyuria, polyphagia as well as drop in body weight. Seventy two hours after the alloxan administration, the animals were fasted overnight and diabetes was confirmed by measuring fasting blood glucose levels with the aid of a single touch glucometer (Fine touch, USA). Only experimental animals that had fasting blood glucose level $>7.0 \mathrm{mmol} / \mathrm{l}(126 \mathrm{mg} / \mathrm{dl})$ were selected for the study (Saidu et al., 2011).

\section{Grouping of Experimental Rats and Studies on Liver Glycogen Content}

The experimental design of Takehiko, (1977) was adopted with modification. The modifications involve the $120 \mathrm{mg} / \mathrm{kg}$ body weight dosage of alloxan for diabetic induction (as against 150-175 $\mathrm{mg}), 36$ hours fasting time for glycogen depletion (as against 48 hours) and non measurement of radioactivity of glycogen. Twenty four (24) 
diabetic and eight normal rats weighing 120 to $150 \mathrm{~g}$ were grouped and treated as follows:

I. Normal rats Fasted (NF).

II. Diabetic rats Fasted (DF).

III. Normal rats, fasted and Re-fed; Untreated (NFRU).

IV. Diabetic rats, Fasted and Re-fed; Untreated (DFRU).

V. Diabetic rats, Fasted, Re-fed and Treated with $300 \mathrm{mg} / \mathrm{kg}$ WO (DFRTwo $)_{3}$.

VI. Diabetic rats, Fasted, Re-fed and Treated with $300 \mathrm{mg} / \mathrm{kg}$ OP (DFRTop).

VII. Diabetic rats, Fasted, Re-fed and Treated with $300 \mathrm{mg} / \mathrm{kg}$ OS (DFRTos 3 ).

VIII.Diabetic rats, Fasted, Re-fed and Treated with $500 \mathrm{mg} / \mathrm{kg}$ Metformin (DFRT $\mathrm{m}$ ).

Groups I and II were humanely sacrificed after 36 hours fasting. The liver glycogen content was assayed to determine the base line for liver glycogen content after 36 hours of fasting. The animals were treated orally per day for a period of one week. Twenty four hours after the last administration, the animals were fasted over night for 12 hours after which they were humanely sacrificed. Blood samples were collected by cardiac puncture into labeled plastic specimen bottles, allowed to clot then centrifuged at $4000 \mathrm{~g}$ for ten minutes before assaying for glucose levels by glucose oxidase/ peroxidase method using Randox kit (Trinder, 1969). The liver surgically excised and placed in normal saline before assaying the liver glycogen content (Kemp and Van-Heijinger, 1954). Briefly, $50 \mathrm{mg}$ weight of liver tissue was minced in a homogenizer with $5 \mathrm{ml}$ of a deprotonizing solution containing $5 \mathrm{~g}$ trichloroacetic acid and $100 \mathrm{mg}$ of silver sulphate dissolved in $100 \mathrm{ml}$ distilled water. The minced fluid was transfered to a centrifuge tube, the level of the fluid was marked and stoppered with a glass cap and then placed in boiling water for 15 minutes. The tubes were removed and cooled under cold tap water. The deprotenizing solution was added up to the marked level to make up for evaporation then centrifuged for 5 minutes at $3000 \mathrm{rpm}$. To $1 \mathrm{ml}$ of the clear supernatant, $3 \mathrm{ml}$ of concentrated $\mathrm{H}_{2} \mathrm{SO}_{4}$ was added in a test tube and vortexed. The mixture was heated in a boiling water bath for 6 minutes, cooled and the intensity of the pink colour formed was measured spectrophotometrically at $520 \mathrm{~nm}$. The glycogen concentration was read from a standard curve.

\section{In vitro Study on the Intestinal Glucose Diffusion}

Glucose diffusion from the Intestine was studied by the method of dialysis tubing technique using rat's intestine (Adiotomre et al., 1990) described as follows: WO, OP, OS and Cellulose (1,2 and $3 \%(w / v))$ were prepared in separate conical flasks each containing $100 \mathrm{ml}$ tyrode solution to which $1.8 \mathrm{~g} / \mathrm{dl}$ glucose was added. Rat intestine for diffusion / dialysis system was prepared using the method of Wilson and Wiseman (1954). Normal adult experimental rats weighing between 120-150 g were selected, fasted for twelve hours (12) with access for clean water. The rats were then anaesthetized and the abdomens were dissected. The entire small intestine was removed quickly by cutting across the upper end of the duodenum and the lower end of the ileum. Carefully, the mesentery in the isolated intestine was stripped manually then rinsed with normal saline solution $(0.9 \% \mathrm{w} / \mathrm{v} \mathrm{NaCl})$ using a plastic syringe. The intestine was cut into $6 \mathrm{~cm}$ long segment and the bottom end ligated by tying with cotton string. Each segment of the intestine was then filled with $1.0 \mathrm{ml}$ of the prepared Okra fruit samples and cellulose in tyrode solution containing $1.8 \mathrm{~g} / \mathrm{dl}$ glucose. Another fragment of intestine was filled with $1.0 \mathrm{ml}$ tyrode solution containing $1.8 \mathrm{~g} / \mathrm{dl}$ glucose but without Okra fruit samples or cellulose; this served as the blank sample. Each segment was distended before the upper end was tied to form a sac. These were then inserted in separate conical flasks each containing $25 \mathrm{ml}$ tyrode solution and incubated at $37{ }^{\circ} \mathrm{C}$ with mild shaking for the dialysis. At 20,40 , 60,80 and 100 minutes, $1 \mathrm{ml}$ each of the dialysate in the conical flasks was taken in triplicate with the aid of pipette and transferred into labeled test tubes. The glucose concentration in each of the test tubes was 
assayed using glucose oxidase/ peroxidase method (Trinder, 1969).

\section{Estimation of Glucose Dialysis Retardation Index (GDRI)}

The glucose dialysis retardation index (Ou et al., 2001), was calculated using the formula below based on the glucose concentrations obtained from each dialysis system above:

GDRI $=100-\frac{\text { Total glucose diffused from sac containing Okra Fruit sample or Cellulose }}{\text { Total glucose diffused from the sac with no Okra Fruit sample or Cellulose) }}$ X 100

\section{Estimation of Glucose Adsorption Capacity (GAC) of the Different Parts of the Okra Fruit} The glucose adsorption capacity $(\mathrm{mmol} / \mathrm{g})$ of Okra samples and cellulose was determined according to the method described by Ou et al., (2001) and Chau et al., (2004) with slight modification. The GAC was calculated as follows:

Glucose adsorpbtion capacity $(\mathrm{GAC})=\mathrm{CGBA}-\mathrm{CGAA}$

CGBA = Glucose concentration before adsorption CGAA = Glucose concentration after adsorption Exactly $1.0 \mathrm{~g}$ each of cellulose and the samples WO, OP and OS were separately mixed with 100 $\mathrm{ml}$ of prepared glucose solution of different concentration $(10,20,30,40$ and $50 \mathrm{mg} / \mathrm{ml})$ in respective conical flasks. The mixtures were stirred, held in a water bath at $37^{\circ} \mathrm{C}$ for 5 hours, followed by centrifugation at $3500 \mathrm{rpm}$ for 15 minutes. At the end of adsorption, the glucose content in each supernatant was measured using the glucose oxidase/ peroxidase method (Trinder, 1969).

\section{Study on possible regeneration of pancreatic islets cells}

The rats for this study were divided in to four (4) groups: [Whole Okra (WO), Okra Peel (OP), Okra Seed (OS) and Control group (C)]. Each of the groups was further sub-divided into two subgroups of six rats each: $\left(\mathrm{WO}_{1}, \mathrm{WO}_{2} ; \mathrm{OP}_{1}\right.$, $\mathrm{OP}_{2}, ; \mathrm{OS}_{1}, \mathrm{OS}_{2}$, ; and $\mathrm{NC}, \mathrm{DC}, \mathrm{MC}$ ) where the subscript 1 and 2 refer to doses of 200 and 300 $\mathrm{mg} / \mathrm{kg}$ body weight of the respective samples to be administered. NC, DC and MC refer to
Normal, Diabetic, and Metformin Controls. The administration was for 21 days. After the expiration of the experimental period, pancreas of rats in each experimental group were identified, isolated and transferred into $10 \%$ formaldehyde to preserve the tissue until when required for the histological studies. Tissue processing was carried out by automatic tissue processing machine (ATP 1027,USA) and the prepared 5micron thickness sections was mounted on slide and stained with hematoxylin \& eosin (H\&E) (Gomeri, 1950). Stained sections were viewed under trinocular phase contrast compound microscope (Labomed, USA). The number of islets per square centimeter in the test groups were counted and scored accordingly based on the method of Findlay and Thomas (1980). The regeneration of pancreatic islets was ranked based on Kruskals - Walis test.

\section{Data Analysis}

The data obtained were presented as mean \pm standard error of the mean. Results were analyzed statistically by one way analysis of variance (ANOVA) followed by post hoc, Duncan test using the statistical package - for Social Sciences (SPSS) software, version 20. A p-value $<0.05$ was considered statistically significant. Mean ranking was done using Kruskals - Walis test 


\section{RESULTS \\ Effect of Administration of Different Parts of Okra Fruit on Liver Glycogen Content and Blood Glucose Levels}

The results of the effect of treatment with different parts (WO, OP and OS) of the Okra fruit on liver glycogen content and fasting blood glucose level are presented in Table 1. The results indicated significant decrease $(p<0.05)$ in the levels of liver glycogen content and blood glucose levels in normal (NF) and diabetic rats (DF) fasted for 36 hours compared to that of normal (NFRU) and diabetic rats (DFRU) that were re-fed for one week after the 36 hours fasting. When the normal fasted rats (NFRU) were re-fed for one week, their fasting blood glucose level and hepatic glycogen content were observed to relatively returned to normal levels $(6.90 \pm 0.62 \mathrm{mmol} / \mathrm{l})$ and $(48.40 \pm 2.52 \mathrm{mg} / \mathrm{g})$ respectively. Whereas, in the fasted, re-fed diabetic rats (DFRU), the fasting blood glucose level $(18.66 \pm 0.72 \mathrm{mmol} / \mathrm{l})$ was significantly $(p<0.05)$ higher than that of the normal rats $(6.90 \pm 0.62 \mathrm{mmol} / /)$. Also, the hepatic glycogen content was found to significantly $(p<0.05)$ decrease $(29.51 \pm 1.96 \mathrm{mg} / \mathrm{g})$ as compared to that of the normal rats $(48.40 \pm 2.52$ $\mathrm{mg} / \mathrm{g}$ ) (Table 1). The effect of treatment with the different parts (WO, OP and OS) of the Okra fruit on liver glycogen content and blood glucose level showed that the fasted alloxan-induced diabetic rats treated with $\mathrm{WO}_{3}, \mathrm{OP}_{3}, \mathrm{OS}_{3}$ for one week after the 36 hours fasting, resulted in significant $(P<0.05)$ increase in the hepatic glycogen content which ranged from $(40.69 \pm 1.44$ to $51.70 \pm 3.51 \mathrm{mg} / \mathrm{g}$ ) while the fasting blood glucose levels were found to significantly $(p<0.05)$ decrease compared to that of fasted diabetic untreated (DFRU) group of rats; and the values were observed to range from $(6.18 \pm 0.46$ to $7.78 \pm 0.65 \mathrm{mmol} / \mathrm{l})$ as compared to that of fasted diabetic untreated (DFRU) group of rats where the liver glycogen content was $(29.51 \pm 1.96 \mathrm{mg} / \mathrm{g})$ and the fasting blood glucose level was $(18.66 \pm 0.72 \mathrm{mmol} / \mathrm{l})$. Similar effect was observed in the Metformin treated group. However, when the liver glycogen content and the fasting blood glucose levels of all the treated groups of rats were compared with one another, it was observed that $\mathrm{WO}_{3}$ showed more increased glycogen content $(51.70 \pm 3.51 \mathrm{mg} / \mathrm{g})$ followed by Metformin control $(47.45 \pm 1.96 \mathrm{mg} / \mathrm{g})$, OP $(43.85 \pm 3.31 \mathrm{mg} / \mathrm{g})$ and lastly the OS $(40.69 \pm 1.44$ $\mathrm{mg} / \mathrm{g})($ Table 1). Table 1: Effect of Administration of Different
Parts of Okra Fruit on Liver Glycogen Content
and Blood Glucose Level

\begin{tabular}{llll}
\hline Group & Title & $\begin{array}{l}\text { Glucose } \\
\text { (mmol/l) }\end{array}$ & $\begin{array}{l}\text { Glycogen } \\
\text { Content } \\
\text { (mg/g) }\end{array}$ \\
\hline I & {$[\mathrm{NF}]$} & $4.43 \pm 0.36^{\mathrm{a}}$ & $3.89 \pm 0.75^{\mathrm{a}}$ \\
ii & {$[\mathrm{DF}]$} & $10.86 \pm 0.72^{\mathrm{c}}$ & $4.79 \pm 0.48^{\mathrm{a}}$ \\
iii & {$[\mathrm{NFRU]}$} & $6.90 \pm 0.62^{\mathrm{b}}$ & $48.40 \pm 2.52^{\mathrm{d}}$ \\
iv & {$[\mathrm{DFRU}]$} & $18.66 \pm 0.72^{\mathrm{d}}$ & $29.51 \pm 1.96^{\mathrm{b}}$ \\
v & {$\left[\mathrm{DFRTwO}{ }_{3}\right]$} & $7.60 \pm 0.71^{\mathrm{b}}$ & $51.70 \pm 3.51^{\mathrm{e}}$ \\
vi & {$\left[\mathrm{DFRTop_{3 } ]}\right.$} & $6.84 \pm 0.12^{\mathrm{b}}$ & $43.85 \pm 3.31^{\mathrm{c}}$ \\
vii & {$\left[\mathrm{DFRTOS_{3 }}\right]$} & $7.78 \pm 0.65^{\mathrm{b}}$ & $40.69 \pm 1.44^{\mathrm{c}}$ \\
viii & {$[\mathrm{DFRTm}]$} & $6.18 \pm 0.46^{\mathrm{b}}$ & $47.45 \pm 1.96^{\mathrm{d}}$ \\
\hline
\end{tabular}

Values are expressed as mean \pm S.E.M., Mean values having different superscript letter in the same column are significantly different at $(P<0.05)$. (NF): Normal rats fasted; (DF): Diabetic rats fasted; (NFRU): Normal rats, fasted, refed untreated; (DFRU): Diabetic rats, fasted, re-fed untreated; (DFRTw03): Diabetic rats, fasted, re-fed and treated with $300 \mathrm{mg} / \mathrm{kg}$ WO; (DFRTop $)$ : Diabetic rats, fasted, re-fed and treated with $300 \mathrm{mg} / \mathrm{kg}$ OP; (DFRTos 3 ): Diabetic rats, fasted, re-fed and treated with $300 \mathrm{mg} / \mathrm{kg}$ OS; (DFRTm): Diabetic rats, fasted, re-fed and treated with $500 \mathrm{mg} / \mathrm{kg}$ Metformin.

\section{Effect of Various Concentrations of Different Parts of Okra Fruit on Intestinal Glucose Diffusion}

The results of the effect of different parts (WO, OP and OS) of the Okra Fruit on diffusion of glucose at different concentration from the mucosal side of the intestine to the outer solution in the container are presented in Table 2. The results showed variation in glucose diffusion at various concentrations of the Okra fruit parts (WO, OP and OS) and Cellulose compared to that of control (solution with no fiber source) as a function of time. It was observed that all the different parts of the Okra fruit significantly $(P<0.05)$ showed decrease glucose diffusion from 
the mucosal side of the various intestinal system containing 1,2 and $3 \%(w / v)$ of Cellulose, WO, $\mathrm{OP}$ and OS to the outer solution compared to that observed in the control system which showed significantly $\quad(P<0.05) \quad$ higher glucose concentrations in the outer solution. The result also indicated that glucose diffusion from the mucosal side of the intestine to the outer solution increases gradually with time in all the sample systems. However, at time 0 to 20 minutes of incubation, there were low amount of diffused glucose in all the dialysate including the control system (which has no fiber source) compared to longer incubation time (Table 2). It was also observed that the significant increments in the amount of diffused glucose from the mucosal sides of the various intestinal system containing $(1,2$ and $3 \% w / v)$ of Cellulose, WO, OP, and OS to the outer solution are statistically $(p<0.05)$ different from one another. When the measured amount of diffused glucose from the mucosal side of the intestine to the outer solutions in the different systems (Cellulose, WO, OP and OS) at time 100 minutes were compared among the groups; the following trends were observed: OP system showed the least amounts of glucose diffused in the dialysate, followed by WO, OS, and finally the Cellulose (Table 2) hence OP could retard glucose diffusion more than the other samples tested.

Table 2: Effect of Various Concentrations of Different Parts of Okra Fruit on Intestinal Glucose Diffusion

\begin{tabular}{|c|c|c|c|c|c|}
\hline \multicolumn{6}{|c|}{ Glucose Concentration in the Dialysate $(\mathrm{mmol} / \mathrm{l})$} \\
\hline Time (min.) & 20 & 40 & 60 & 80 & 100 \\
\hline Celu.1\% & $0.22 \pm 0.01 \mathrm{~d} 1$ & $0.38 \pm 0.01^{\mathrm{e} 2}$ & $1.75 \pm 0.01 \mathrm{j} 3$ & $1.95 \pm 0.01 \mathrm{k} 4$ & $2.05 \pm 0.0315$ \\
\hline $2 \%$ & $0.15 \pm 0.00 \mathrm{c} 1$ & $0.32 \pm 0.01 \mathrm{~d} 2$ & $1.51 \pm 0.01^{i 3}$ & $1.81 \pm 0.01 j 4$ & $1.83 \pm 0.01 \mathrm{k} 5$ \\
\hline $3 \%$ & $0.11 \pm 0.00^{\mathrm{b} 1}$ & $0.16 \pm 0.01^{\mathrm{b} 2}$ & $1.25 \pm 0.01^{\mathrm{h} 3}$ & $1.71 \pm 0.01^{i 4}$ & $1.72 \pm 0.01 j^{4}$ \\
\hline W0.1\% & $0.11 \pm 0.01 \mathrm{~b} 1$ & $0.42 \pm 0.01^{12}$ & $0.71 \pm 0.01 \mathrm{~d} 3$ & $1.11 \pm 0.01^{f 4}$ & $1.22 \pm 0.0155$ \\
\hline $2 \%$ & $0.10 \pm 0.01 \mathrm{~b} 1$ & $0.34 \pm 0.01 \mathrm{~d} 2$ & $0.61 \pm 0.01 c 3$ & $1.01 \pm 0.01 \mathrm{e} 4$ & $1.05 \pm 0.04 \mathrm{e} 4$ \\
\hline $3 \%$ & $0.10 \pm 0.00^{b 1}$ & $0.31 \pm 0.01 \mathrm{~d} 2$ & $0.55 \pm 0.00^{c 3}$ & $0.81 \pm 0.01 \mathrm{~d} 4$ & $0.90 \pm 0.00 \mathrm{~d} 5$ \\
\hline OP.1\% & $0.05 \pm 0.00 a^{a 1}$ & $0.21 \pm 0.01^{\mathrm{c} 2}$ & $0.41 \pm 0.00^{\mathrm{b} 3}$ & $0.65 \pm 0.00^{c 4}$ & $0.66 \pm 0.01^{c 4}$ \\
\hline $2 \%$ & $0.05 \pm 0.00 \mathrm{a} 1$ & $0.15 \pm 0.01^{b 2}$ & $0.37 \pm 0.01^{b 3}$ & $0.51 \pm 0.01 \mathrm{b4}$ & $0.56 \pm 0.01^{\mathrm{b} 5}$ \\
\hline $3 \%$ & $0.05 \pm 0.01 \mathrm{a} 1$ & $0.10 \pm 0.01^{\mathrm{a} 1}$ & $0.20 \pm 0.05^{\mathrm{a} 2}$ & $0.23 \pm 0.06^{\mathrm{a} 2}$ & $0.35 \pm 0.00^{\mathrm{a} 3}$ \\
\hline OS.1\% & $0.25 \pm 0.00^{\mathrm{e} 1}$ & $0.71 \pm 0.01^{i 2}$ & $1.15 \pm 0.00^{3} 3$ & $1.41 \pm 0.0194$ & $1.51 \pm 0.0115$ \\
\hline $2 \%$ & $0.25 \pm 0.00 \mathrm{e}^{\mathrm{N}}$ & $0.61 \pm 0.01 \mathrm{~h} 2$ & $1.07 \pm 0.04^{f 3}$ & $1.36 \pm 0.01 \mathrm{gh} 4$ & $1.43 \pm 0.03^{\mathrm{h} 5}$ \\
\hline $3 \%$ & $0.25 \pm 0.00^{e} 1$ & $0.51 \pm 0.019^{2}$ & $0.93 \pm 0.04 \mathrm{e} 3$ & $1.32 \pm 0.01 \mathrm{gh} 4$ & $1.36 \pm 0.0194$ \\
\hline Cnt.0\% & $0.41 \pm 0.01^{f 1}$ & $1.35 \pm 0.02^{j 2}$ & $2.02 \pm 0.01 \mathrm{k3}$ & $2.24 \pm 0.01^{14}$ & $2.28 \pm 0.02^{\mathrm{m} 4}$ \\
\hline
\end{tabular}

Values are expressed as mean \pm S.E.M., Mean values having different superscript letter and figure in the same column and row respectively are significantly different at $(\mathrm{P}<0.05)$ Celu\%: $(1 \%, 2 \%$ and $3 \%$ w/v) Cellulose solution; WO $\%$ : $(1 \%, 2 \%$ and $3 \%$ w/v) whole Okra solution; OP\%: (1\%, $2 \%$ and $3 \%$ w/v) Okra peel solution; OS\%: (1\%, 2\% and 3\%) Okra seed solution; Cnt\%. Control (0\% Okra).

\section{Effect of Various Concentrations of Different Parts of Okra Fruit on Glucose Dialysis Retardation Index (GDRI)}

The results of the effect of different concentrations of different parts (WO, OP and OS) of the Okra fruit on Glucose dialysis retardation index (GDRI) is presented in Table 3. Generally, the maximum values of GDRI were reached after 40 minutes in all the test samples. The results also reflect that the GDRI values were reduced consecutively as incubation time increases from 60 to 100 minutes. The glucose diffusion was maximally retarded at 40 minutes where the GDRI of OP sample ranges from $84.44 \pm 0.10$ to $92.33 \pm 0.28 \%$ were significantly $(P<0.05)$ higher than WO and OS, this was 
followed by that of Cellulose (control) which ranges from $71.83 \pm 0.52$ to $87.86 \pm 0.9 \%$, the next was WO sample with GDRI values ranging from $69.10 \pm 0.72$ to $77.27 \pm 0.25 \%$ while OS sample have the least GDRI values which range from $47.12 \pm 1.08$ to $61.98 \pm 0.20 \%$ (Table 3 ).

\section{In-vitro Glucose Adsorption Capacity (GAC) of Different Parts of Okra Fruit in Various \\ Concentrations of Glucose}

The results of glucose adsorption capacity (GAC) of different parts (WO, OP and OS) of the Okra fruit in various glucose concentrations are presented in Table 4. Generally, the results showed that all parts of the Okra fruit (WO, OP, and OS) could bind glucose and the adsorption capacity significantly $(P<0.05)$ increases in each sample as the concentration of glucose in the sample increases. The glucose adsorption capacity (GAC) of all the different parts of the Okra fruit are found to be significantly $(P<0.05)$ different with one another even at the same concentration of glucose (Table 4). It was also observed that the GAC of Cellulose at 10 to 50 $\mathrm{mmol} / \mathrm{l}$ glucose concentrations ranged from $(0.27 \pm 0.024$ to $4.43 \pm 0.024 \mathrm{mmol} / \mathrm{g})$, that of WO ranged from $(0.74 \pm 0.017$ to $6.20 \pm 0.025 \mathrm{mmol} / \mathrm{g})$ while in the $O P$ and $O S$, it ranges from $(1.02 \pm 0.012$ to $8.44 \pm 0.020 \mathrm{mmol} / \mathrm{g})$ and $(0.45 \pm 0.012$ to $4.95 \pm 0.029 \mathrm{mmol} / \mathrm{g})$ respectively. However, when the GAC of the different samples were compared, the OP sample showed the highest GAC, followed by WO then OS and lastly Cellulose sample.

\section{Table 3: Effect of Various Concentrations of Different Parts of Okra Fruit on Glucose Dialysis Retardation Index (GDRI)}

\begin{tabular}{cccccc}
\hline & \multicolumn{5}{c}{ Glucose Dialysis Retardation Index (\%) } \\
Time (min.) & $\mathbf{2 0}$ & $\mathbf{4 0}$ & $\mathbf{6 0}$ & $\mathbf{8 0}$ & $\mathbf{1 0 0}$ \\
\hline Cel.1\% & $47.00 \pm 3.00^{\mathrm{b}}$ & $71.83 \pm 0.52^{\mathrm{e}}$ & $13.38 \pm 0.80^{\mathrm{a}}$ & $12.81 \pm 0.86^{\mathrm{a}}$ & $10.22 \pm 1.40^{\mathrm{a}}$ \\
$2 \%$ & $61.67 \pm 0.33^{\mathrm{c}}$ & $76.25 \pm 0.93^{\mathrm{g}}$ & $25.28 \pm 0.41^{\mathrm{b}}$ & $19.07 \pm 0.24^{\mathrm{b}}$ & $19.72 \pm 0.38^{\mathrm{b}}$ \\
$3 \%$ & $73.67 \pm 0.67^{\mathrm{d}}$ & $87.86 \pm 0.91^{\mathrm{i}}$ & $37.84 \pm 0.08^{\mathrm{c}}$ & $23.54 \pm 0.48^{\mathrm{c}}$ & $24.26 \pm 0.46^{\mathrm{c}}$ \\
\hline W01\% & $72.00 \pm 2.08^{\mathrm{d}}$ & $69.10 \pm 0.72^{\mathrm{d}}$ & $64.62 \pm 0.23 \mathrm{~g}$ & $50.37 \pm 0.37^{\mathrm{f}}$ & $46.63 \pm 0.16^{\mathrm{g}}$ \\
$2 \%$ & $75.33 \pm 1.45^{\mathrm{d}}$ & $74.76 \pm 0.96^{\mathrm{f}}$ & $54.78 \pm 0.54^{\mathrm{f}}$ & $54.68 \pm 0.45^{\mathrm{g}}$ & $53.78 \pm 2.01^{\mathrm{h}}$ \\
$3 \%$ & $74.33 \pm 0.67^{\mathrm{d}}$ & $77.27 \pm 0.25^{\mathrm{g}}$ & $72.38 \pm 0.14^{\mathrm{h}}$ & $63.78 \pm 0.33^{\mathrm{h}}$ & $62.37 \pm 1.92^{\mathrm{i}}$ \\
\hline OP.1\% & $87.56 \pm 0.03^{\mathrm{e}}$ & $84.44 \pm 0.10^{\mathrm{h}}$ & $79.83 \pm 0.12^{\mathrm{i}}$ & $70.94 \pm 0.11^{\mathrm{i}}$ & $71.04 \pm 0.09^{\mathrm{j}}$ \\
$2 \%$ & $87.72 \pm 0.19^{\mathrm{e}}$ & $88.88 \pm 0.36^{\mathrm{i}}$ & $82.31 \pm 0.23^{\mathrm{i}}$ & $77.34 \pm 0.29^{\mathrm{j}}$ & $75.29 \pm 0.22^{\mathrm{k}}$ \\
$3 \%$ & $87.82 \pm 1.32^{\mathrm{e}}$ & $92.33 \pm 0.28^{\mathrm{j}}$ & $87.60 \pm 0.07^{\mathrm{j}}$ & $89.55 \pm 2.98^{\mathrm{k}}$ & $84.50 \pm 0.05^{\mathrm{l}}$ \\
\hline OS.1\% & $39.81 \pm 1.19^{\mathrm{a}}$ & $47.12 \pm 1.08^{\mathrm{a}}$ & $42.80 \pm 0.41^{\mathrm{d}}$ & $36.95 \pm 0.50^{\mathrm{d}}$ & $33.76 \pm 0.46^{\mathrm{d}}$ \\
$2 \%$ & $38.20 \pm 0.44^{\mathrm{a}}$ & $54.78 \pm 0.53^{\mathrm{b}}$ & $46.91 \pm 2.0^{\mathrm{e}}$ & $39.33 \pm 0.34^{\mathrm{e}}$ & $37.14 \pm 1.04^{\mathrm{e}}$ \\
$3 \%$ & $38.99 \pm 0.86^{\mathrm{a}}$ & $61.98 \pm 0.20^{\mathrm{c}}$ & $53.86 \pm 1.95^{\mathrm{f}}$ & $40.82 \pm 0.75^{\mathrm{e}}$ & $40.34 \pm 0.18^{\mathrm{f}}$ \\
\hline
\end{tabular}

Values are expressed as mean \pm S.E.M., Mean values having different superscript letter in the same column are significantly different at ( $\mathrm{P}<0.05)$ Cel\%: $(1 \%, 2 \%$ and $3 \%$ w/v) Cellulose solution ( control); WO $\%:(1 \%, 2 \%$ and $3 \%$ w/v) whole Okra solution; OP\%: (1\%, $2 \%$ and $3 \%$ w/v) okra peel solution; OS\%: (1\%, $2 \%$ and $3 \%)$ okra seed solution.

Table 4: Glucose adsorption capacity (GAC) of different parts of okra fruit in various concentrations of glucose

\begin{tabular}{lccccc}
\hline & \multicolumn{5}{c}{ Glucose concentration (mmol/l) } \\
Sample (g) & $\mathbf{1 0}$ & $\mathbf{2 0}$ & $\mathbf{3 0}$ & $\mathbf{4 0}$ & $\mathbf{5 0}$ \\
\hline 1.0 Cell. & $0.27 \pm 0.024^{\mathrm{a}}$ & $0.72 \pm 0.02^{\mathrm{b}}$ & $2.04 \pm 0.011^{\mathrm{c}}$ & $3.06 \pm 0.0^{\mathrm{d}}$ & $4.43 \pm 0.024^{\mathrm{e}}$ \\
1.0 WO. & $0.74 \pm 0.017^{\mathrm{a}}$ & $1.27 \pm 0.01^{\mathrm{b}}$ & $2.67 \pm 0.018^{\mathrm{c}}$ & $4.81 \pm 0.01^{\mathrm{d}}$ & $6.20 \pm 0.025^{\mathrm{e}}$ \\
1.0 OP. & $1.02 \pm 0.012^{\mathrm{a}}$ & $1.96 \pm 0.02^{\mathrm{b}}$ & $3.82 \pm 0.027^{\mathrm{c}}$ & $5.67 \pm 0.01^{\mathrm{d}}$ & $8.44 \pm 0.020^{\mathrm{e}}$ \\
1.0 OS. & $0.45 \pm 0.012^{\mathrm{a}}$ & $1.03 \pm 0.01^{\mathrm{b}}$ & $2.36 \pm 0.012^{\mathrm{c}}$ & $3.47 \pm 0.01^{\mathrm{d}}$ & $4.95 \pm 0.029 \mathrm{e}$ \\
\hline
\end{tabular}

Values were expressed as mean \pm S.E.M., Mean values having different superscript letter in the same row are significantly $(\mathrm{P}<0.05)$ different.1.0 Cell: $1.0 \mathrm{~g}$ of Cellulose; $1.0 \mathrm{WO}: 1.0 \mathrm{~g}$ of Whole Okra; $1.0 \mathrm{OP}: 1.0 \mathrm{~g}$ of Okra Peel; $1.0 \mathrm{OS}: 1.0 \mathrm{~g}$ of Okra Seed. 


\section{Effect of Administration of Different Parts of the Okra Fruit on Pancreatic Islets}

The results of the effect of treatment with different parts (WO, OP and OS) of the Okra fruit on pancreatic islets are depicted in Table 6 and Plates 1 to 6 . The results were based on the quantitative counting of the number of islets per square centimetre of the processed pancreatic sections stained with hematoxylin and eosin $(\mathrm{H}$ and E). The results (Table 5) showed that diabetic untreated group (DC) had no scores on number of islets [-].The islets in such group were relatively absent [-] [No islet seen per low power field (x100)] in comparison with normal control group which shows the presence of many islets [+++] per low power field (x100).

Table 5: Effect of Administration of Different Parts of the Okra Fruit on Number of Islets per Square Centimetre in the Stained Pancreatic Tissues

\begin{tabular}{||l||l|l||l||}
\hline \multicolumn{1}{|c||}{ Group } & \multicolumn{3}{c|}{ Number of Islets } \\
\hline \hline $\mathrm{NC}$ & + & ++ & +++ \\
\hline $\mathrm{DC}$ & - & - & - \\
\hline $\mathrm{MC}$ & + & - & ++ \\
\hline $\mathrm{WO} \mathrm{O}_{2}$ & + & - & + \\
\hline \hline $\mathrm{WO}_{3}$ & - & + & +++ \\
\hline \hline $\mathrm{OP}_{2}$ & - & + & - \\
\hline $\mathrm{OP}_{3}$ & - & - & + \\
\hline \hline $\mathrm{OS}_{2}$ & - & - & + \\
\hline $\mathrm{OS}_{3}$ & - & + & ++ \\
\hline
\end{tabular}

NC: Normal Control, DC: Diabetic Control, MC: Metformin Control $500 \mathrm{mg} / \mathrm{kg}$ body weight of Metformin; $\mathrm{WO}_{2}, \mathrm{WO}_{3}: 200$ \& $300 \mathrm{mg} / \mathrm{kg}$ body weight of Whole Okra., $\mathrm{OP}_{2}$, \& $\mathrm{OP}_{3}: 200$ \& $300 \mathrm{mg} / \mathrm{kg}$ body weight of Okra Peel and OS $2, \& \mathrm{OS}_{3}: 200$ \& $300 \mathrm{mg} / \mathrm{kg}$ body weight of Okra Seed

[-]: No islet seen per low power field (x100) [Severe damage/No regeneration]

[+]: Very few Islets per low power field (x100) [Mild regeneration of Pancreas]

[++]: Few Islets per low power field (x100) [Moderate regeneration of Pancreas]

[+++]: Many Islets per low power field (x100) [Normal Pancreas]

Results (Table 5) of the effect of treatments with the different parts (WO, OP, and OS) of the Okra fruit at doses of 200 and $300 \mathrm{mg} / \mathrm{kg}$ body weight and that of Metformin after three weeks showed mild to moderate improvement in the number of islet per square centimeter of the stained pancreas in all the treated groups as ranked based on Kruskals - Walis test (Table 6). However, the mild regeneration of number of islet were seen in the $\mathrm{OP}_{2}, \mathrm{OP}_{3}$ and $\mathrm{OS}_{2}$ treated groups while the moderate regeneration of number of islet were seen in the $\mathrm{MC}, \mathrm{OS}_{3}$ and especially in the $\mathrm{WO}_{3}$ group(Table 6)

Table 6: Mean ranking for the level of regeneration of Islet using Kruskal-Wallis

Test

\begin{tabular}{lc}
\hline Group & $\begin{array}{c}\text { Mean Ranks for Level of } \\
\text { Regeneration of Islets }\end{array}$ \\
\hline$[\mathrm{NC}]$ & $22.83^{\mathrm{a}}$ \\
{$[\mathrm{DC}]$} & $7.00^{\mathrm{b}}$ \\
{$[\mathrm{MC}]$} & $16.33^{\mathrm{c}}$ \\
{$\left[\mathrm{WO}_{2}\right]$} & $14.33^{\mathrm{c}}$ \\
{$\left[\mathrm{WO}_{3}\right]$} & $17.17^{\mathrm{c}}$ \\
{$\left[\mathrm{OP}_{2}\right]$} & $10.67^{\mathrm{d}}$ \\
{$\left[\mathrm{OP}_{3}\right]$} & $10.67^{\mathrm{d}}$ \\
{$\left[\mathrm{OS}_{2}\right]$} & $10.67^{\mathrm{d}}$ \\
{$\left[\mathrm{OS}_{3}\right]$} & $16.33^{\mathrm{c}}$
\end{tabular}

Values were expressed as Mean Ranks for the levels of regeneration of the pancreatic Islets as follows:

a: Normal pancreas. b: No regeneration of Pancreas.c: Moderate Regeneration of Pancreas. d: Mild Regeneration of Pancreas.NC: Normal Control, DC: Diabetic Control, MC: Metformin Control $(500 \mathrm{mg} / \mathrm{kg})$ body weight of Metformin; $\mathrm{WO}_{2}, \mathrm{WO}_{3}$ : $(200 \& 300 \mathrm{mg} / \mathrm{kg})$ body weight of Whole Okra., $\mathrm{OP}_{2}$, \& $\mathrm{OP}_{3}:(200 \& 300 \mathrm{mg} / \mathrm{kg}$ ) body weight of Okra Peel and $\mathrm{OS}_{2}, \& \mathrm{OS}_{3}:(200 \& 300 \mathrm{mg} / \mathrm{kg}$ ) body weight of Okra Seed.

\section{DISCUSSION}

The results of the effect of 36 hours fasting on liver glycogen content and blood glucose levels (Table 1) of normal (NF) and diabetic (DF) rats indicated significant decrease $(p<0.05)$ in the levels of fasting blood glucose and liver glycogen content. 


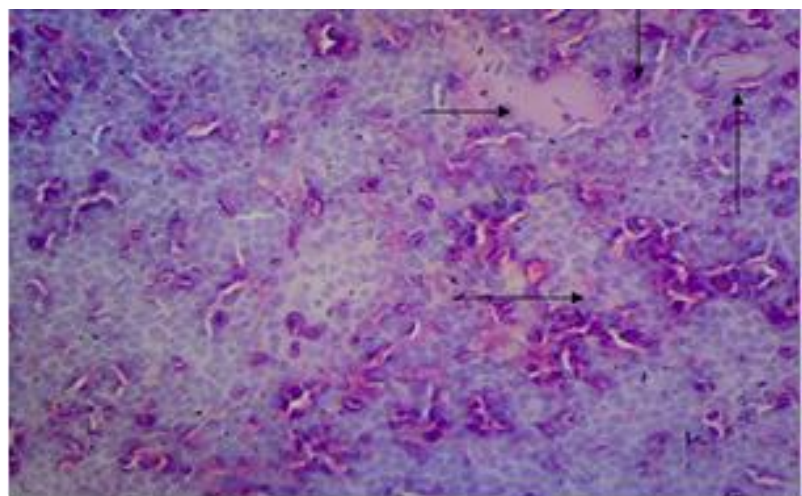

Plate 1: Light Photomicrograph of Normal Rat pancreas tissue (Hematoxylin and Eosin Staining) showing pancreas with [+++] Islets per low power field (x100).

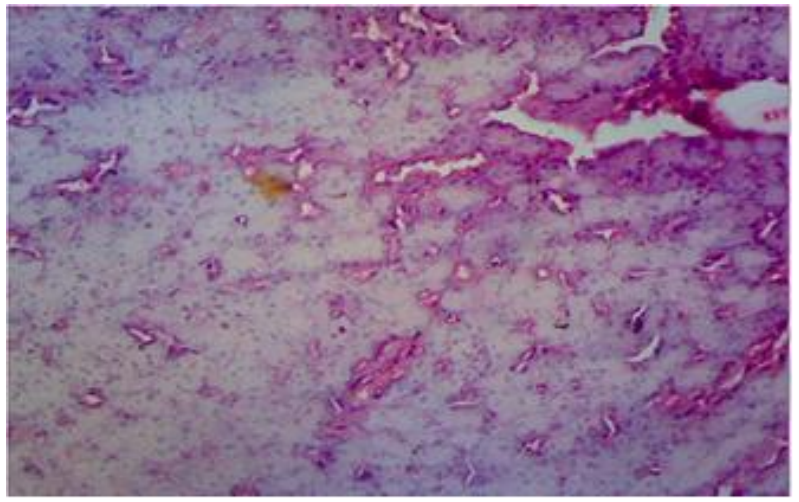

Plate 2: Light Photomicrograph of Diabetic Rat pancreas tissue (Hematoxylin and Eosin Staining) showing pancreas with no [-] Islets per low power field (x100).

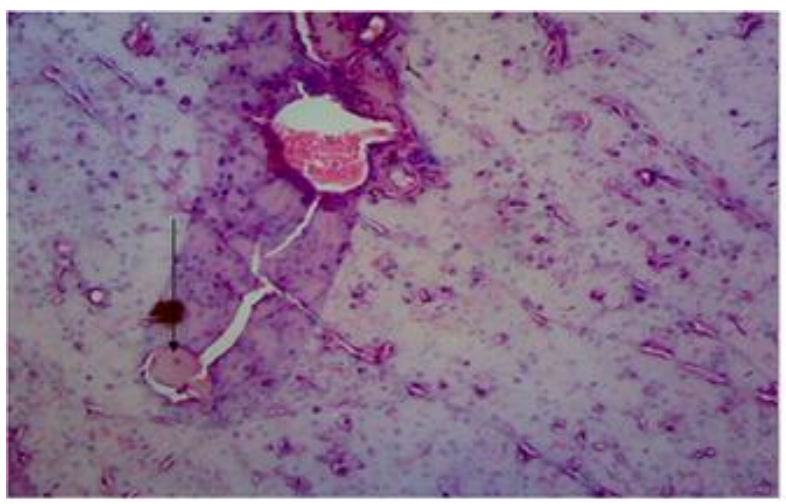

Plate 3: Light Photomicrograph of MC group pancreas tissue (Hematoxylin and Eosin Staining) showing pancreas with [+] Islets per low power field (x100).

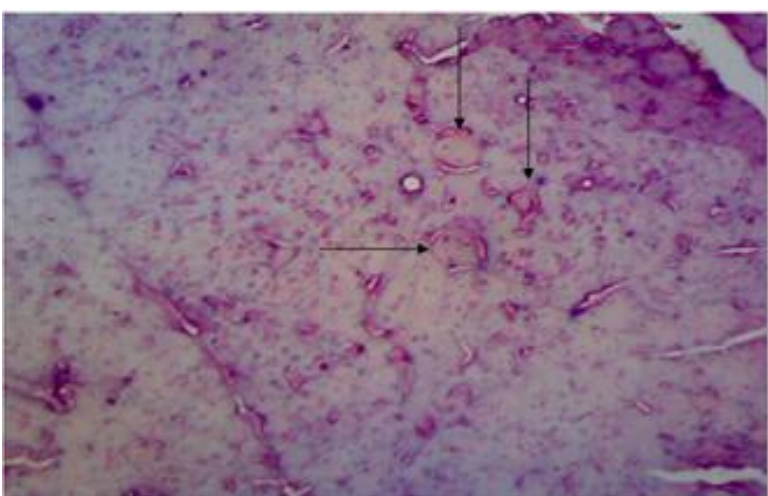

Plate 4: Light Photomicrograph of WO group pancreas tissue (Hematoxylin and Eosin Staining) showing pancreas with [+++] Islets per low power field $(\mathrm{x} 100)$.

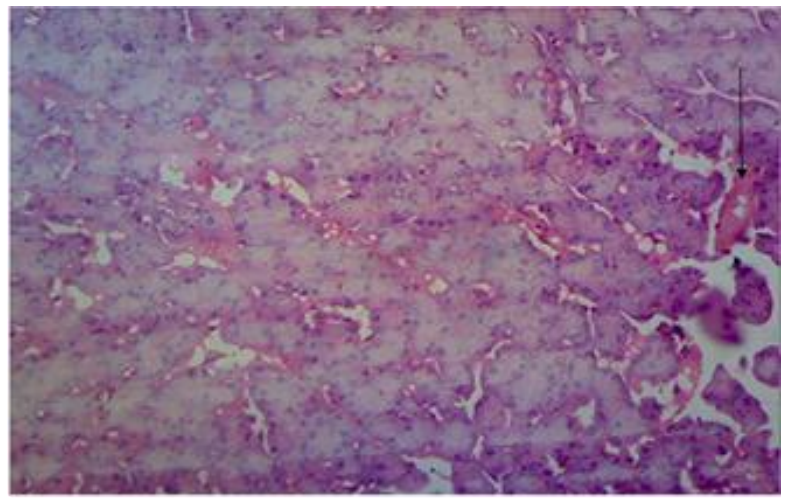

Plate 5: Light Photomicrograph of OP group Pancreas tissue (Hematoxylin and Eosin Staining Showing pancreas with $[+]$ Islets per low power field (x100).

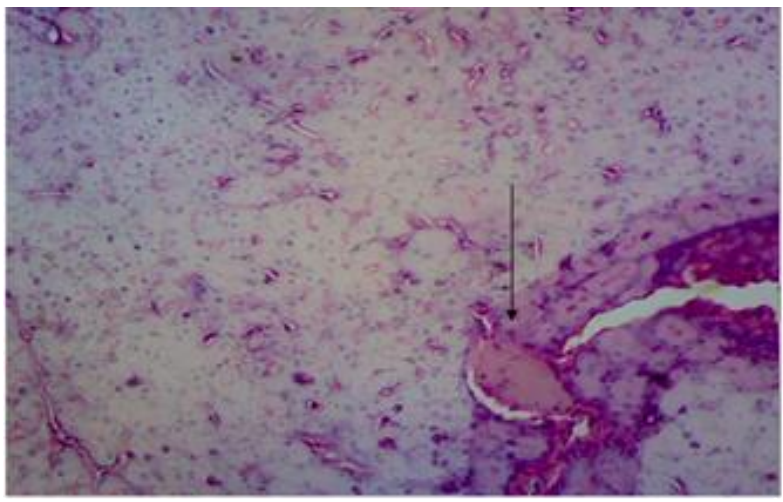

Plate 6:Light Photomicrograph of OS group pancreas. (Hematoxylin and Eosin Staining) showing pancreas with [+] Islets per low power field $(x 100)$. 
This finding is in line with other findings that reported depleted glycogen content and blood glucose levels in prolonged fasting (Morita and Orten, 1950; Renold et al., 1953; Friedmann et al., 1965; Ross, 1967 and Nilesh et al., 2012). The current study showed that fasting blood glucose level returns to normal range while the hepatic glycogen content was significantly $(P<0.05)$ replenished in normal untreated (NFRU) rats that were re-fed for one week after fasting for the 36 hours. But, in diabetic fasted, re-fed, untreated (DFRU) group of rats, the reverse was the case, where the fasting blood glucose level remains significantly $(p<0.05)$ higher than that of the normal while the liver glycogen contents was found to be significantly $(p<0.05)$ lower compared to that of the normal group of the fasted rats (NFRU) (Table 1). This is in agreement with the findings of Renold et al., 1953; Friedmann et al., 1965; Ross, 1967; Anderson, 1974 and Nilesh et al., 2012. The reduction in hepatic glycogen content and increased blood glucose levels in the diabetic rats as compared to that of the normal group could be due to the destruction of the pancreatic cells caused by the alloxan which leads to inadequate insulin secretion and this could results in decrease synthesis of glycogen and increase in glycogenolysis and gluconeogenesis (Sumana and Suryawashi, 2001). The current results clearly show that diabetic rats fasted for 36 hours, re-fed and treated with different parts of the Okra fruit $\left(\mathrm{WO}_{3}\right.$, $\mathrm{OP}_{3}$ and $\mathrm{OS}_{3}$ ) at the doses of $300 \mathrm{mg} / \mathrm{kg}$ for one week resulted in significant $(p<0.05)$ decrease in fasting blood glucose level while the hepatic glycogen content increases significantly $(p<0.05)$ as compared with the diabetic control (DFRU) groups (Diabetic rats, fasted, re-fed untreated). Similar results was also found in the other group of diabetic rats (DFRT $\mathrm{m}$ ) after fasting for the 36 hours, re-fed and treated with $500 \mathrm{mg} / \mathrm{kg}$ Metformin for one week. Although, all the treatment with the different parts of the Okra fruit (WO, OP and OS) maintained the blood glucose level within the normal ranges (Table 1), However, the hepatic glycogen content was found to increase more in the $\mathrm{WO}_{3}$ treated group followed by that $\mathrm{OP}_{3}$ and the least was $\mathrm{OS}_{3}$ group. This showed the significant antidiabetic effect of Okra fruit especially the $\mathrm{WO}_{3}$ group which showed the highest liver glycogen content. The significant increase in liver glycogen content in the fasted diabetic rats treated with $\left(\mathrm{WO}_{3}, \mathrm{OP}_{3}\right.$ and $\mathrm{OS}_{3}$ ) may be due to the activation of glycogen synthase system and deactivation of glycogen phosphorylase system. This may be due to activation of glycogen synthase by some constituents in the Okra fruit or by stimulating insulin secretion leading to increase glycogenesis via glycogen synthase activation (Gaw et al., 1998). This insulin mimetic effect was also reported for other medicinal plants such as magnifera indica leaves (Aderibigbe et al., 2001), Salacia. Chinensis roots (magniferin) (Periyar et al., 2009). Similar observations, i.e. hypoglycemic activity and improved levels of hepatic glycogen, were reported by Roffey, (2007) in diabetic animals treated with Momordica charantia for eight weeks. It was therefore suggested that the increase in liver glycogen could possibly be due to either stimulation of insulin release or due to insulomimetic activity of some component of the Okra fruit resulting in direct peripheral glucose uptake.

Postprandial hyperglycemia plays an important role in the incidence of DM, since recent studies suggest that it could induce the non-enzymatic glycosylation of various proteins, resulting in the development of chronic complications (Caspary, 2001). Therefore, controlling its level, via retarding intestinal glucose diffusion and absorption is believed to be an important strategy to manage this disease. In this study, it was observed that different parts of the Okra fruit significantly $(p<0.05)$ decrease glucose diffusion from the mucosal side of the various intestinal system containing 1, 2 and $3 \%(w / v)$ of Cellulose, WO, $\mathrm{OP}$ and OS to the outer solution compared to that observed in the control system which has significantly $\quad(p<0.05) \quad$ higher glucose concentrations in the outer solution. It was observed that Okra peel sample has the least amount of diffused glucose followed by WO then 
OS and lastly Cellulose. The retardation effect of dietary fiber on glucose diffusion and absorption was mainly due to their viscosity and fibrous nature (Ou et al., 2001). Jenkins et al.,(1986) indicated that the retardation in glucose diffusion and absorption due to fibers was affected by viscosity of the intestinal content. Also, Lopez, (1996) and Nishimune, (1991) opined that glucose diffusion might be affected by adsorption of glucose on fiber and viscosity. The results of the current study might suggest that the retardation of glucose diffusion from the mucosal side of the intestine to the outer solution might be due to the physical binding and entrapment of glucose within the network of the fibers. This effect was observed more in the OP followed by WO then OS and finally, the least was Cellulose. This is because OP sample was observed to be more viscous than the rest of the samples tested. Thus, Ex-maradi Okra fruit fibers have effects in delaying glucose diffusion and subsequently decrease glucose absorption in gastrointestinal tract and hence can reduce postprandial hyperglycemia. The glucose diffusion retardation effect of the fibers, in addition to their viscosity might be probably attributed to their adsorption capacity (Ou et al., 2001).

Glucose dialysis retardation index (GDRI) is a useful in vitro index to further predict the effect of dietary fiber on the delay in glucose absorption in the gastrointestinal tract (Lopez, 1996; Ou et al., 2001 and Longstreth et al., 2006). The results obtained from the current study showed variation in GDRI in the presence of various concentrations of different parts (WO, OP and OS) of the Okra fruit. Based on the results, OP and WO showed the highest GDRI and could effectively control postprandial hyperglycemia. Akhtar and Iqbal, (1991) and Frati-Munari et al., (1988) reported that hypoglycemic effects can be due to decreased intestinal glucose absorption when provoked by the presence of dietary fiber and viscosity. These findings have been supported by the suggestion made by $\mathrm{Ou}$ et al., (2001) who advocated that "Severe postprandial hyperglycemia commonly experienced by diabetics could be prevented if the rate of glucose uptake from the intestine into the blood circulation could be reduced by inhibiting carbohydrate digestion and absorption". This will result in diminished and delayed rise in postprandial glucose concentration, leading to normal glucose homeostasis in diabetic subjects.

Another useful in vitro method used to further predict the effect of dietary fiber on the delay of postprandial glucose concentration is by measuring the glucose adsorption capacity (GAC) of a sample (Ou et al., 2001). The current study revealed that all the different parts (WO, $\mathrm{OP}$ and OS) of the Okra fruit have different glucose adsorption capacity that is concentration dependent (Table 4). This is in agreement with the findings of $\mathrm{Ou}$ et al., (2001) where they reported that insoluble fiber derived from wheat bran could adsorb glucose at different concentrations. At lower glucose concentration $(10 \mathrm{mmol} / \mathrm{l})$, the OP showed the highest GAC, followed by WO, then OS where as Cellulose (control) had the least GAC. Similar trends were observed at higher glucose concentration (50 $\mathrm{mmol} / \mathrm{l})$. It could be suggested that adsorption of glucose by Okra fibers might be attributed to the increased water holding capacity and viscosity of the fibers which indicated that the fiber might help to retain glucose in the intestinal lumen and this could be beneficial with respect to reducing amount of accessible glucose absorbed from the small intestine. The present results were in agreement with the findings of Blackburn, (1984) and Chau et al; (2004) where they reported that glucose adsorption capacity of fibers is directly related to the available glucose concentration.

One of the possible mechanisms of antidiabetic effect of plant is enhanced insulin secretion by regeneration of damaged pancreatic islets cells (El-Abhar, 2014). So, the current study investigated the possible regenerative effects of Okra fruit part on damaged pancreatic islets cells. It was observed that Islets in the pancreatic tissues of the diabetic untreated rats (Plate 1) were severely damage with associated necrotic 


\section{Nigerian Journal of Basic and Applied Science (December, 2017), 25(2): 101-113}

changes of the pancreatic islets, nuclear changes, karyolysis, and disappearance of nucleus when compared to that of the normal control (NC) group (Plate 2). Based on the current results, the diabetic untreated group (DC) had zero score [-] on the number of islets per square centimetre under low power field (x100). The absence of islets (Plate 2) could be due to the selective destruction of pancreatic $\beta$ cells by the Alloxan. The findings of the current study showed (Plate 3) mild to moderate improvement in the number of islet per square centimeter of the stained pancreas in all the treated groups as ranked based on Kruskals - Walis test. These signify the pancreatic regeneration effect of the Ex-maradi Okra fruit variety. Base on this finding, we suggest that whole Okra fruit may contain some vital nutrients and other Phytochemicals which could play role in stimulation of regenerative process of damaged pancreatic cells. Okra is also regarded as treasure house of polyphenolic compounds (Habtamu et al., 2014) and contribute to its antioxidant property and hence inhibiting the formation of lipid peroxides and other destructive free radicals (Habtamu et al., 2014). The antioxidant property of phenolic compounds in Okra might also be part of mechanisms for repair and regeneration of the damaged pancreatic cells. This result is consistent with some earlier reports on regeneration of $\beta$ cells. Flavonoid fraction extracted from pterocarpus marsupium was reported to resulted in decrease in blood glucose level and increase in number of pancreatic beta cells (Chakravarthy et al., 1980). Nigella sativa in combination with gliclazide was also reported to increase the number of beta cells (Abdel-Moneim et al., 1999). Two (2) plant components (GS4 and GS3) extracted from Gymnema sylvestera were reported to decrease blood glucose and increase number of beta cells and islets in diabetic rats (Shanmugasundaram et al., 1990).

\section{CONCLUSION}

The possible mechanism of antidiabetic effects of Ex-maradi Okra fruit might involve stimulation of glycogenesis, delay intestinal glucose diffusion, increase glucose adsorption capacity and possible regeneration of pancreatic islets cells. These mechanisms may significantly contribute to the control of postprandial hyperglycemia that is important in management of diabetes mellitus.

\section{REFERENCES}

Abdel-Moneim, A., EL-Feki, M., Salah E. (1999). Effect of Nigella sativa, fish oil and gliclazide on alloxan-diabetic rats. IBiochemical and histo-pathological studies. Journal of Egypt-German. Society of Zoology, 23(A):237-265.

Aderibigbe, A. O., Emudianughe T. S., Lowal, B. A. (2001). Evaluation of Antidiabetic Activation of Magnifera indica in mice. Phytotherapy Research, 15: 456-458.

Adiotomre, J., Eastwood, M.A, Edwards, C.A., Brydon, W.G. (1990). Dietary Fiber: Invitro Methods that Anticipate Nutrition and Metabolic Activity in Humans. American Journal Clinical Nutrition, 52: 128-134.

Akhtar, M.S. and lqbal, J.(1991). Evaluation of the hypoglycaemic effect of Achyranthes aspera in normal and alloxan-diabetic rabbits. Journal of Ethnopharmacology, 31(1):49-57

Anderson, J. W. (1974). "Alterations in Metabolic Fate of Glucose in the Liver of Diabetic Animals,"American Journal of Clinical Nutrition, 27(7): 746-755.

Blackburn, N. A. (1984). The Mechanism of Action of Guar Gum in Improving Glucose-tolerance in Man. Clinical Science, 66(3): 329-336.

Caspary, W.F. (2001). Sucrose Malabsorption in Man After Ingestion of aglucosidehydrolase Inhibitor. Lancet; 1 : 1231-1233.

Chau, C.F., Chen, C.H., Lee, M.H. (2004). Comparison of the Characterstics, Functional Propoties \& in vitro Hypoglycemic Effects of Various Carrot Insoluble Fibre Rice Fractions. Lebensmittel-Wissenschaft Technologie, 37: 155-160. 
Chauhan, G.S., Dhiman, S.K., Guleria, L.K.(2001). Polymer from renewable resources: kinetic studies of the radiochemical graft copolymerization of styrene onto cellulose extracted from pine needles and the effect of some additives on the grafting parameters in an aqueous medium. Journal of Applied Polymer Science, 83: 1490- 1500.

El-Abhar, H.S. and Schaalan, M.F. (2014). Phytotherapy in diabetes: Review on potential mechanistic perspectives. World Journal of Diabetes, 5(2): 176-197.

Etuk, E.U., and Mohammed, B.J. (2009). Informant consensus selection method: A reliability assessment on medicinal plants used in north western Nigeria for the treatment of diabetes mellitus. African Journal Pharmacy and. Pharmacology, 3(10):496-500.

Findlay, J.A. and Thomas, N.W. (1980). Histology and Cytology of the Islets of Langerhans in the Mongolian gerbil Merion's Ungiculatus. Acta Anatomica, 108: 446462.

Frati-Munari, A.C., Gordilla, B.E., Altamirano, P., Ariza, C.R. (1988). Hypoglycaemic Effect of Opuntia Streptacanthalemaire in NIDDM. Diabetes Care 11: 63-66.

Friedmann, B., Goodman, E.H. and Weinhouse, S. (1965). Dietaryand Hormonal Effects on Gluconeogenesis in the rat, Journal of Biological 01em, 240: 3729.

Habtamu, F.G., Negussie, R., Gulelat, D.H., Ashagrie, Z. (2014). Nutritional Quality and Health Benefits of Okra (Abelmoschus Esculentus): A Review, Global Journal of Medical Research: Interdisciplinary; 14 (5): 1.

Jenkins, D.J.A., Jenkins, M.J.A., Wolver, T.M.S., Taylor, R.H., Ghafari, H. (1986). Slow Release Carbohybrate: Mechanism of Action of Viscous Fiber. Journal Clinical Nututrition and Gastroenterology 1: 237-241.

Kemp, A. and Van-Heijinger, A. J. (1954). A colorimetric Micro-method for the
Determination of Glycogen in Tissue. Biochemical Journal, 56: 64-68.

Longstreth, G.F., Thompson, W.G., Chey, W.D., Houghton, L.A., Mearin, F. and Spiller, R.C. (2006), "Functional Bowel Disorders," Gastroenterology, 130: 14801491.

Lopez, G., Ros, G., Rinicon, F., Periago, M.J., Mertinez, M.C. (1996). Relationship Between Physical and Hydration Properties of Soluble and Insoluble Fiber of Artichoke. Journal of Agriculture and Food Chemistry, 44: 2773-2778.

Mishra, A., and Jha, S. (2011). In vitro Postprandial Glucose Lowering Effect of Dietary Fibers Isoltated from Tamarindusindica and Cassia Fistuka Seeds. American Journal of Food Technology, 6(5): 435-440.

Morita, Y. and Orten, J.M. (1950). Glycogen Content of Liver of Alloxan Diabetic Rat, American Journal of Physiolology, 161: 545.

Nilesh J., Ruchi J., Vaibhav J. and Surendra J.(2012) A Review on : Abelmoschus esculentus. Pharmacia 1(3):84-89

Nishimune, T., Yakushiji, T., Sumimoto, T., Taguchi, S.,Konishi, Y. (1991). Glycemic Response and Fiber Content of Some Foods. American Journal of Clinical. Nutrutrition, 54: 414-419.

Ou, S., Kwok, K., Li, Y., Fu, L. (2001). In-vitro Study of Possible Role of Dietary Fiber in Lowering Postprandial Serum Glucose. Journal of Agriculture and Food Chemistry 49: 1026-1029.

Periyar, S.S., Balu, P.M., Sathiya, M. P., Murugesan, K. (2009). Antihyperglycemic Effect of Magniferin in Streptozotocininduced Diabetic Rats. Journal of Health Science; 55(2): 206- 214.

Renold, A.E., Tenz, C.T., Nesbett, F.B. and Hastings, A.B. (1953). Studies on Carbohydrate Metabolismin Rat Liver Slice, Journal of Biological 01em, 204:533. 
Roffey, B.W., Atwal, A.S., Johns, T., Kubow, S. (2007). Water Extracts from Momordica charantia Increase Glucose Uptake and Adiponectin Secretion in 3T3-L1 Adipose Cells. Journal of Ethnopharmacolology, 112: $77-84$.

Ross, B.D., Hems, R., Freedland, R.A.,Krebs, H.A. (1967). Carbohydrate Metabolism of the Perfused Rat Liver. Biochemical Journal, 105: 869.

Saidu, Y., Nwachukwu, F.C., Bilbis, L.S., Faruk, U.Z., Abbas, A.Y. (2011). Hypoglycaemic and Hypolipidemic Effects of Root Extracts of Albizzia chevalieri in Alloxan Induced Diabetic Rats. Nigerian Journal of Basic and Applied Science 18(1):72-78.

Shanmugasundaram, E. R. B., Rajeswari, G., Baskaran, K., Kumar, R. B. R., Shanmugasundaram, K. R.,Ahmath, B. K. (1990), Use of Gymnema sylvestre leaf extract in the control of blood glucose in insulin-dependent diabetes mellitus. Journal of Ethnopharmacoologyl, 30, 281-94
Shokeen, P., Anand, P., Murali, Y.K., Tandon, V. (2008). Antidiabetic Activity of $50 \%$ Ethanolic Extract of Ricinus communis and its Purified Fractions. Food Chememistry and Toxicology. 46: 345866.

Sumana, G. and Suryawashi, S.A. (2001). Effect of Vinca rosea Extracts in Treatment of Alloxan Diabetes in Male Albino Rats. Indian Journal of Experimental. Biology, 39: $748-758$.

Takehiko, K. (1977). Analysis of A Characteristic Alteration of Glycogen in the Liver of Alloxan Diabetic Rat by Fasting. Nagoya Journal of Medical Sciences, 39: 59-67

Trinder, P. (1969). Determination of Blood Glucose in Blood Using Glucose Oxidase with an Alternative Oxygen Acceptor. Annals of Clinical. Biochemistry, 6: 2425.

WHO (1999) WHO Study Group Report on Diagnosis and Classification of Diabetes Mellitus. WHO, Study Group. Geneva; (WHO Technical Report Series No. 849). WHO (2016) Global report on Diabetes, Geneva 